\title{
Inglês para crianças do Ensino Fundamental: visões implícitas da avaliação proposta por um livro didático e as crenças dos professores ${ }^{1}$
}

Cláudia Hilsdorf Rocha

Universidade Estadual de Campinas (UNICAMP)

Leny Costa

Universidade Estadual de Campinas (UNICAMP)

Faculdade Comunitária de Limeira (FAC-Limeira)

Kleber Aparecido da Silva

Faculdade Comunitária de Limeira (FAC-Limeira)

Doutorando da UNESP (IBILCE - São José do Rio Preto)

\begin{abstract}
Este trabalho, de natureza qualitativa e de cunho etnográfico, tem como cenário um Projeto de Línguas Estrangeiras, implementado nos Ciclos 1 e 2 do Ensino Fundamental Público de uma cidade do interior paulista. O objetivo principal do estudo é investigar as visões implícitas da avaliação proposta pelo livro didático em uso no mencionado contexto de ensino, confrontando-as com a abordagem explícita do material acerca do processo avaliatório e com as crenças dos professores sobre a avaliação em foco. Para tanto, tomamos como referencial os princípios sociointeracionistas (VYGOTSKY, 1978) e comunicacionais (ALMEIDA FILHO, 1993, 2005) de linguagem e aprendizagem, assim como construtos referentes às crenças sobre ensino e aprendizagem de línguas (BARCELOS, 1995, 2004a, b; SILVA, 2005) e também referentes à avaliação (SCARAMUCCI, 1997, 2004) no ensino de línguas para crianças (CAMERON, 2001).
\end{abstract}

\footnotetext{
${ }^{1}$ Este artigo é fruto das reflexões desenvolvidas na disciplina "Avaliação em Lingua Estrangeira/Segunda Lingua”, ministrada pela Professora Dra. Matilde Virginia Ricardi Scaramucci, no Instituto de Estudos da Linguagem (IEL) da Universidade Estadual de Campinas (UNICAMP), no segundo semestre letivo de 2005. Este estudo tem sua origem marcada também pelas dissertações de Silva (2005) e Rocha (2006), ambas desenvolvidas na mencionada Instituição, sob a orientação do Professor Dr. José Carlos Paes de Almeida Filho. Agradecemos imensamente a ambos os docentes citados pelas valiosas contribuições ao texto produzido. As falhas remanescentes permanecem sob nossa inteira responsabilidade.
} 
This qualitative and ethnographic study was carried out within the context of a Foreign Language Project implemented in the Municipal Primary Schools of a small city in the state of São Paulo State. This research aimed at investigating the implicit and explicit views of the evaluation proposed by the coursebook in use. This work also aimed at researching into the relationship between such views and the beliefs of the teachers involved in such evaluation process. The theoretical framework includes reference to the communicative (ALMEIDA FILHO, 1993, 2005) and socio-interactionist principles (VYGOTSKY, 1978, 1998, 2001) applied to the concept of beliefs (BARCELOS, 1995, 2004a, b; SILVA, 2005), as well as on constructs related to testing and assessment (SCARAMUCCI, 1997, 2004) as far as Primary English teaching is concerned (CAMERON, 2001).

\begin{abstract}
"A Lingüística Aplicada preocupa-se com os mais emotivos e importantes assuntos: a educação das crianças, os direitos dos menos favorecidos, o equilíbrio não estável das culturas e línguas, os efeitos da tecnologia na comunicação (...) Há muitas vozes falando para a Lingüística Aplicada (...) é preciso ouvir a todas elas (...) e falar com a própria voz"
\end{abstract}

(COOK, 2003, p. 78)

\title{
Introdução
}

Em uma sociedade globalizada, em que o contato com diferentes culturas e línguas cada vez mais se intensifica através dos meios de comunicação e da tecnologia, entre outros, o ensino/aprendizagem de línguas estrangeiras (doravante LE) assume um papel fundamental. Dentro desse contexto, não sem controvérsias, o inglês é hoje considerado como a língua universal, assumindo status oficial em cerca de sessenta países e proeminência em pelo menos vinte, conforme asseveram Brewster, Ellis e Girard (2002).

Dessa forma, tem sido também crescente a necessidade do conhecimento e o interesse pela aprendizagem dessa língua, dentre outras, em todo o mundo, sendo hoje uma forte tendência que o processo se inicie cada vez mais cedo. Tanto autores internacionais como brasileiros atestam que vivenciamos hoje um grande interesse pelo ensino de LE para crianças (LEC daqui por diante), tanto em contexto de escolas regulares como em institutos de idiomas, e enfatizam ser essa uma área ainda muito carente de pesquisas (CAMERON, 2001; BRUMFIT, MOON; TONGUE, 1995; HOUSE, 1997; LUZ, 2003; entre outros). 
Ainda dentro da área de ensino/aprendizagem de línguas, podemos ressaltar o crescente interesse pela influência que as crenças (BARCELOS, 2000, 2001, 2004a, SILVA, 2005), também chamadas de teorias implícitas (WILLIAMS; BURDEN, 1997), exercem dentro do processo. Segundo Pajares (1992), a definição do termo é ainda complexa e controversa. De um modo geral, entendemos por crenças as concepções, idéias, opiniões, valorações que alunos, professores e terceiros (pais, coordenadores, diretores, entre outros) possuem a respeito do que é ensinar e aprender uma língua, sendo que uma definição mais detalhada do conceito será apresentada no referencial teórico deste estudo.

O número cada vez maior de estudos sobre o referido tema (ALANEN, 2003; BARCELOS, 1995, 2001, 2003, 2004a, b; SILVA, 2005; somente para citar alguns) é um forte indicador da importância de se investigarem quais são as implicações e influências das crenças dos agentes para o contexto de ensino/aprendizagem no qual estão inseridos. No que se refere à avaliação, considerada como uma das materialidades do processo de ensino/aprendizagem de LE que merece especial atenção por seu potencial (re)direcionador do processo (SCARAMUCCI, 1997, 2004), a importância de se investigarem as crenças também se faz presente.

Conforme Rolim (2004), a falta de compreensão por parte de um grande número de professores a respeito da função educativa da avaliação faz com que a prática avaliativa fique reduzida à mera verificação de erros e acertos produzidos pelos alunos, sendo essa prática ainda vista como um instrumento de punição, de promoção e de controle. Essa visão reducionista da educação, segundo a referida autora, é perpetuada, entre outros fatores, através da aparente incapacidade dos Cursos de Letras em propiciar oportunidades de reflexão e questionamentos a respeito de pressupostos teóricos concernentes à avaliação.

Mediante a falta de uma formação adequada, o professor de LE tende a inconscientemente legitimar concepções limitadas sobre a avaliação, uma vez que geralmente orienta sua prática pedagógica baseando-se em "concepções intuitivas, crenças e mitos construídos ao longo das experiências de ensino e de aprendizagem do que seja avaliar" (ROLIM, op. cit., p. 139). Scaramucci (1993) define esse conjunto (na maioria das vezes implícito) de idéias e concepções que o professor tem a respeito da avaliação como "cultura de avaliar", reforçando, dessa forma, a influência das crenças no processo de ensino/aprendizagem 
de LE e a importância de as mesmas serem investigadas. É importante ressaltar, contudo, que apesar de ser reconhecida como um aspecto importante dentro do processo de ensino/aprendizagem, a avaliação não tem sido, dentro do contexto nacional, foco intenso de estudos.

Dessa forma, considerando-se a explicitada importância da avaliação no processo de ensino/aprendizagem de línguas e mediante o pressuposto de que o conhecimento implícito move a ação do professor (SCHÖN, 1983), torna-se extremamente importante que investiguemos as crenças dos professores frente à ação de ensinar e avaliar, visando a uma melhor compreensão do processo. Retomando a constante expansão do ensino de LE para crianças na sociedade atual, como também a escassez de estudos nessa área (CAMERON, 2001, 2003; LUZ, 2003; ROCHA, 2006; dentre outros), torna-se igualmente relevante que estudemos a relação das crenças sobre avaliação dentro do referido contexto.

Tomando-se como foco um Projeto de Línguas Estrangeiras para crianças dos ciclos 1 e 2 do Ensino Fundamental Público de uma cidade do interior paulista, este estudo originou-se da necessidade de se investigarem as crenças dos professores de LE (inglês) frente à avaliação proposta pelo material didático em uso, a fim de compreendermos como as teorias implícitas desses professores e os princípios que norteiam a mencionada avaliação relacionam-se dentro desse contexto específico.

A relevância desta pesquisa recai, ainda, na possibilidade de se promoverem transformações no contexto mencionado, visando a minimizar possíveis dicotomias relacionadas aos aspectos que dizem respeito ao processo avaliatório, contribuindo para que o processo de ensino de LEC torne-se mais efetivo e menos contraditório nesse sentido. Ressalte-se que as alterações almejadas não são diretamente decorrentes deste estudo, ou seja, da explicitação das crenças dos professores e dos princípios que embasam a avaliação em foco, mas, sim, de um trabalho em devir, calcado na prática reflexiva acerca da questão em estudo e de seus resultados (SMITH, 1992; dentre outros) envolvendo professores e coordenadores do Projeto acima citado (doravante PL).

\section{Objetivos e Perguntas de Pesquisa}

Mediante a já explicitada importância de se investigarem as crenças referentes à avaliação de professores inseridos em um contexto de ensinar 
LE (Inglês) a alunos dos Ciclos 1 e 2 do Ensino Fundamental Público de uma cidade do interior paulista frente aos princípios que explicitamente norteiam o processo de avaliação proposto pelo livro didático (LD) em uso no referido contexto, os objetivos do trabalho proposto são os que seguem:

a) investigar as visões implícitas na avaliação proposta por um material didático específico em uso no curso de Inglês do Projeto de Línguas em foco, frente aos objetivos explicitados neste material e às teorias e construtos sobre avaliação dentro de um contexto de ensino de inglês para crianças dos ciclos 1 e 2 do Ensino Fundamental Público de uma cidade do interior paulista;

b) investigar possíveis semelhanças e diferenças entre os referenciais teóricos privilegiados e explicitados neste estudo e as crenças dos professores-participantes no que se refere à avaliação em foco; e

c) estabelecer possíveis modificações (ou não) na referida avaliação, a fim de, mediante os resultados obtidos em 1 e 2 acima, torná-la (se necessário) mais consistente com o contexto e o referencial teórico adotado nesta pesquisa.

As perguntas de pesquisa que operacionalizam os objetivos propostos são explicitadas abaixo.

a) Quais as abordagens implícitas da avaliação proposta pelo LD em questão? O quanto as abordagens implícitas da avaliação são consonantes ou dissonantes dos referenciais teóricos defendidos neste estudo, das abordagens explícitas do material didático, definidas através dos objetivos por ele propostos, bem como das visões e concepções dos participantes frente à avaliação?

b) Quais as possíveis modificações que a avaliação proposta pelo LD deve sofrer (caso conclua-se necessário) para que ela se torne mais consonante com os princípios defendidos neste trabalho no que se refere à avaliação?

\section{Referencial Teórico}

O Ensino de Línguas tem recebido tratamentos diversos ao longo da história, sendo estes embasados e motivados por uma síntese das diferentes visões de linguagem e dos conceitos de aprender e ensinar Língua 
Estrangeira (LE). Dentre as principais teorias de linguagem e aprendizagem de línguas, a saber, a behaviorista, a cognitivista e a socioconstrutivista, este estudo privilegia esta última, também conhecida como teoria histórico-cultural, teoria sociocultural ou abordagem sociointeracionista (REGO, 2004), por entender, principalmente, que a linguagem é um veículo para as relações interpessoais (WILLIAMS; BURDEN, 1997), ou seja, pode definir-se como prática socioculturalmente constituída (VYGOTSKY, 1978, 1998, 2001).

A visão educacional aqui tomada embasa-se em Moita Lopes (1996), que, por sua vez, apóia-se nas idéias de Bruner (1986) e Vygotsky (1978), e advoga que a educação é um processo essencialmente cultural e social, no qual alunos e professores participam interagindo na construção de um conhecimento conjunto. Conforme acentua Rocha (2006), essa visão de linguagem nos permite dialogar com princípios freirianos, os quais advogam que a educação é, também, um ato político e "que ensinar exige reconhecer que a educação é ideológica" (FREIRE, 2004, p. 125). Tais premissas são, por sua vez, convergentes com a importância de desenvolvermos, através do ensino, uma postura consciente e crítica frente à linguagem e à sociedade, o que está, em nossa acepção, intrinsecamente relacionado ao conceito de educação como prática libertadora (FREIRE, 1988, 1996, 2004).

Os referenciais mencionados são basilares para nosso trabalho por encontrarem-se alinhados à idéia de prática da linguagem em contextos socialmente e historicamente constituídos e, portanto, situados. Tais premissas convergem, assim, com a concepção de que as práticas envolvendo o uso da LE devem ser voltadas para a construção de sentidos, de forma natural e significativa, ou seja, de maneira condizente com a forma com que a linguagem é usada na interação social real.

Portanto, a presente pesquisa fundamenta-se, principalmente, nos pressupostos teóricos do sociointeracionismo (VYGOTSKY, 1978, 1998, 2001), que, ao implicar a concepção do desenvolvimento e da aprendizagem do indivíduo como sendo algo socialmente construído, toma como referencial primário a mediação no processo. Dessa forma, os ambientes gerados no processo de ensino/aprendizagem de LE devem propiciar a construção do conhecimento através da interação, visando à formação de cidadãos críticos, responsáveis e atuantes na vida social (Cf. ROCHA, 2006). 
Dentro da área de ensino/aprendizagem de LE, especificamente, tais pressupostos são corroborados por princípios da Abordagem Comunicativa (ALMEIDA FILHO, 1993, 1997, 2005), a qual está ancorada, principalmente, na concepção de linguagem como um meio para a comunicação (WIDDOWSON, 1978) e não como um sistema de formas e regras passíveis de serem internalizados. É importante aqui ressaltar que, conforme salienta Almeida Filho (2005, p. 80), os referenciais que norteiam a referida abordagem mantêm uma estreita relação com o conceito de competência comunicativa proposto por Hymes $(1967,1972)$, o qual abrange não somente competência lingüística mas também a sociolingüística ou pragmática. Posteriormente, Canale e Swain (1980) e Canale (1983) propõem a didatização da noção de competência comunicativa e, ao relacioná-la explícita e diretamente ao ensino de línguas, descrevem o conceito como sendo constituído pelas competências lingüística (ou gramatical), sociolingüística, discursiva e estratégica.

Dentro de perspectivas da Abordagem Comunicativa, portanto, devemos ensinar línguas para e como comunicação humana, privilegiando a negociação de sentidos no processo de aprendizagem da língua-alvo (WIDDOWSON, 1990) e, ainda, colocando maior ênfase no que faz sentido para o aprendiz, bem como no que o faz crescer como pessoa e cidadão, fazendo com que o processo de ensinar e aprender LE seja constituído pela "dimensão social, cultural e eventualmente política” (ALMEIDA FILHO, 2005, p. 99).

Encontramos apoio em Brewster, Ellis e Girard (2002) acerca dos referenciais teóricos relacionados ao ensino comunicativo, privilegiados neste estudo, à medida que os citados autores consideram os princípios norteadores da AC convergentes com os pressupostos constitutivos do sociointeracionismo. Os mencionados autores (BREWSTER; ELLIS; GIRARD, 2002, p. 44) destacam que a abordagem comunicativa e a sociointeracionista partilham das mesmas concepções, as quais "enfatizam a natureza social da aprendizagem de línguas e a interação". Nessa perspectiva, torna-se relevante pontuar que entendemos, nesta pesquisa, serem o sociointeracionismo e o comunicativismo duas variantes muito próximas, que se originam de uma abordagem (ALMEIDA FILHO, 1993, 2005) de língua/linguagem como comunicação e, portanto, como prática socioculturalmente organizada.

É pertinente salientar que Brewster, Elis e Girard (2002) chamam nossa atenção para o fato de que a AC recebe críticas por privilegiar o 
ensino de funções comunicativas em detrimento da cultura. Da mesma forma, diversos teóricos criticam essa abordagem, por entenderem que a mesma aproxima seu foco do aprendiz adulto ao privilegiar a seqüência de interações "apresentação-prática-consolidação", a qual se apresenta distante da necessidade do aprendiz criança de (co)construir seu conhecimento, estando constantemente engajado na ação, focando a realidade imediata. A AC é também alvo de apreciações desfavoráveis, pelo seu aparente distanciamento de uma abordagem crítica frente ao processo educativo (PENNYCOOK, 1990) e, portanto, de uma visão ideológica da linguagem (COX; ASSIS-PETERSON, 2001).

A esse respeito, contra-argumentamos que os princípios da AC, (re)vistos sob uma perspectiva atual (OLIVEIRA SANTOS, 2004; ALMEIDA FILHO, 2005, dentre outros), não mantêm uma relação dicotômica com teorias cuja concepção de linguagem é a de prática social, em que o indivíduo é visto como um ser social e político (VYGOTSKY, 1998; BAKHTIN, 2004; FREIRE, 1988, 1996, 2004). Caminhando nessa direção, Almeida Filho (2005, p. 81) afirma que, dentro de premissas comunicativas, "aprender uma língua não é mais somente aprender outro sistema, nem só passar informações a um interlocutor, mas sim construir no discurso (...) ações sociais (e culturais) apropriadas".

O autor (ALMEIDA FILHO, 2005, p. 81) prossegue enfatizando que o discurso deve ser concebido como uma linguagem "com fins específicos", sendo

(...) marcado por diferenças individuais em situações sócio-culturais reais, nas quais o (inter)locutor se depara com a manutenção das relações sociais, conflitos, necessidades de informações e negociações, sempre sob o prisma de atitudes, motivações pessoais ou coletivo-culturais.

Desse modo, à medida que se vincula o Comunicativismo ao uso da língua dentro de instituições e grupos sociais, socioculturalmente marcados, podemos asseverar que o referido autor alinha seu pensamento às premissas vygotskianas, não tornando conflitante um diálogo entre a AC e uma visão crítica da linguagem e do ensino/ aprendizagem de línguas.

Em outras palavras, conforme ressalta Rocha (2006), uma visão renovada da AC, abordada por autores como Thompson (1996), Prabhu (2003), Almeida Filho (2005), entre outros, permite que seus princípios sejam "revisitados", como o fez Ur (1995), possibilitando que dimensões 
críticas e pragmáticas sejam acopladas ao ensino comunicativo, porém sem descaracterizá-lo. Nesse sentido, Rocha (op. cit.) enfatiza que teorias e abordagens, assim como a sociedade e o indivíduo, estão em constante transformação, devendo, portanto, ser continuamente (re)construídas a partir de seu cerne.

Uma série de posturas e ações referentes ao processo de ensinar e aprender LE podem ser consideradas comunicativas, segundo Almeida Filho (2005). Dentre elas, destacamos as que compactuam com os princípios sociointeracionais defendidos neste estudo, tais como a concepção do aprendiz como agente no processo de formação através de uma nova língua, a predominância de conteúdos que propiciem a prática da LE como experiência válida para a formação (integral) e crescimento intelectual do aluno, ênfase na representação de temas e conflitos do universo do aluno em forma de problematização dialógica e atividades processuais, cujo foco recai no processo de comunicação socioculturalmente constituída e não na forma, única e explicitamente, como também a atenção a variáveis afetivas.

De acordo com Rocha (op. cit.), a AC compactua com princípios sociointeracionais defendidos atualmente por muitos autores dentro do processo de ensino/aprendizagem de LEC, dentre eles Brewster, Ellis e Girard (2002) e Cameron (2001), uma vez que a mesma defende um processo de ensino/aprendizagem embasado em interações significativas, com ênfase no uso da LE em situações reais e situadas de comunicação. Dentro dessa perspectiva, tais concepções implicam uma visão de aprendizagem como processo de constante (re)construção de conhecimento, no qual o aprendente é visto como participante ativo, co-responsável pela sua aprendizagem, e o professor, por sua vez, é considerado mediador desse processo.

Rocha (op. cit.) enfatiza, ainda, que perspectivas comunicacionais não impedem que objetivos metacognitivos (BRUNER, 1986) sejam desenvolvidos dentro do ensino de LEC, conforme propõe Ellis (2004), Brewster, Ellis e Girard (2002), dentre outros, nem tampouco invalidam uma abordagem crítica (FREIRE, 2004) do processo educacional (MENEGHINI, 2004). Na verdade, tais princípios são corroborados pela AC em tempos atuais, à medida que ela defende a reflexão (SHÖN, 1983; ZEICHNER, 1993; SMITH, 1992) ao longo do processo, no que diz respeito aos professores de LE (VIEIRA-ABRAHÃO, 2004, entre outros), 
aos alunos (BARCELOS, 2001, 2003, 2004a, b) e corrobora idéias ligadas ao desenvolvimento da cidadania (ALMEIDA FILHO, 2005) e à formação (integral) do aluno.

No âmbito da Escola Pública, contexto focado neste estudo, princípios Socio-interacionistas (VYGOTSKY, 1978, 1998, 2001), através dos PCN-LE, que são explicitamente embasados em uma visão sociointeracionista de linguagem e de aprendizagem, fundamentam o atual Ensino Fundamental e Médio e compartilham com a Abordagem Comunicativa (ALMEIDA FILHO, 1993, 1997, 2005), dentro do contexto de ensino de línguas estrangeiras, a idéia de uma abordagem de ensinar mais comprometida com a qualidade das interações em sala de aula. Segundo tais referenciais, o processo de ensino de LE deve propiciar momentos de interação capazes de construir espaços propícios à "construção e transformação" e não à "transmissão de conhecimentos", visando à formação de cidadãos críticos, responsáveis e atuantes na vida social, o que nos remete à concepção de Prabhu (1992) da sala de aula como um evento social em toda sua amplitude.

Esta pesquisa está também calcada no pressuposto de que todos os sujeitos envolvidos dentro do processo de ensino/aprendizagem possuem concepções, crenças, atitudes e idéias próprias a respeito desse processo - o que é aqui concebido como Teoria Implícita ou Informal do processo de aprender e ensinar línguas (ALMEIDA FILHO, 1993, 1997) - e que essa teoria fortemente influencia o processo de ensino/ aprendizagem. Buscando embasamento em Schön $(1983,1987)$ e Zeichner (1993), entre outros, podemos afirmar que a ação do professor é resultante de suas teorias implícitas, conceito este também concebido por muitos autores como crenças. De maneira geral e sucinta, Barcelos (1995, 2001, 2004a) concebe crenças como socialmente constituídas através da interação social, sendo, portanto, contextuais, sociais e dinâmicas.

Dentro dessa visão, elas podem ser definidas como o conjunto de idéias, imagens, memórias e interpretações que o indivíduo tem a respeito de algo, no caso, do processo de ensinar e aprender línguas. Segundo Barcelos (2004a, p. 132), as crenças devem ser "vistas como parte da cultura de ensinar e aprender; representações sobre o processo de ensinar e aprender em uma determinada sociedade" e também como "específicas do contexto e investigadas a partir de sua origem dentro do contexto de suas ações". 
Conscientes de não haver uma definição única do conceito de crenças sobre o processo de ensinar e aprender línguas, convergimos com Silva (2005) no que diz respeito à concepção do referido termo. Esse autor define crenças sobre o ensino e aprendizagem de línguas como

idéias ou conjunto de idéias para as quais apresentamos graus distintos de adesão (conjecturas, idéias relativamente estáveis, convicção e fé). As crenças na teoria de ensino e aprendizagem de línguas são essas idéias que tanto alunos, professores e terceiros ${ }^{2}$ têm a respeito dos processos de ensino/aprendizagem de línguas e que se (re) constroem neles mediante as suas próprias experiências de vida e que se mantêm por um certo período de tempo. (SILVA, 2005, p. 77).

Retomamos também a concepção de que as crenças são complexas, dinâmicas, paradoxais, contraditórias; estão relacionadas intimamente ao nosso eu, ou seja, à nossa própria identidade, conforme salientado por Barcelos (2004a, 2004b, 2000), Silva (2005, no prelo). Vale salientar ainda que as crenças são interativas, emergentes, recíprocas; são vistas como social e, portanto, também cultural e historicamente constituídas através da interação do sujeito com o contexto, possuindo uma estreita relação com a ação (Cf. KALAJA, 1995; KALAJA; BARCELOS, 2003; BARCELOS, 2004a, 2004b; SILVA, 2005, no prelo; entre outros).

Outra variável que está intrinsecamente relacionada com a natureza das crenças sobre o ensino e aprendizagem de línguas é que elas têm um componente afetivo ("pet beliefs", DEWEY, 1933), fruto dos sentimentos e das avaliações de experiências. Pois, segundo Nespor (1987), as crenças são compostas de inúmeros fatores, dentre eles emoções, expectativas, sentimentos, valorações e percepções que se firmam como atitudes, posturas do professor/aprendiz frente ao processo de ensinar/aprender uma LE. As crenças, segundo Silva (2005, p. 78), "seriam um acervo vivo de verdades individuais ou coletivas, ${ }^{3}$ na

\footnotetext{
2 Para Silva (2005, p. 77), "terceiros" ou "cultura de terceiros" são os "os outros agentes participantes do processo educacional, tais como o coordenador, diretor e/ou proprietário da escola; autores de documentos educacionais (Parâmetros Curriculares Nacionais, Leis e Diretrizes e Bases para a Educação, etc.), pais, dentre outros".

${ }^{3}$ Por exemplo, um grupo de pessoas, no nosso caso alunos e professores, pode compartilhar de uma mesma crença.
} 
maioria das vezes implícitas, (re)construídas ativamente nas experiências, que guiam a ação do indivíduo e podem influenciar a crença de outros que estejam ou não inseridos na sala de aula".

No que se refere à avaliação no ensino/aprendizagem de LE, Scaramucci (1997, p. 77) salienta que a prática avaliativa em nosso sistema educacional está calcada em uma visão limitada da avaliação como instrumento "promocional, índice do status do aluno e até mesmo de controle disciplinar". Dentro dessa visão reducionista, a prática da avaliação, conforme aponta Rolim (2004), limita-se à mera verificação de erros e acertos. Corroborando o pensamento das autoras citadas, Luckesi (1986/2003) assevera que geralmente a prática da avaliação resume-se em classificar o aluno em um determinado nível de aprendizagem. Segundo Scaramucci (op. cit.), a visão reducionista acima explicitada é reforçada pela natureza ameaçadora inerente a essa forma de avaliação.

Mediante a reconhecida ineficácia dessa forma de avaliação (ROLIM, 2004), que é essencialmente classificatória e somativa e que tem como foco unicamente o produto, evidencia-se a necessidade de reflexão frente à função da avaliação dentro de um processo de ensinar e aprender uma LE embasado em concepções contemporâneas, as quais privilegiam uma visão de linguagem como um meio de comunicação e a aprendizagem como um processo contínuo de (re)construção de conhecimento conjunto. Nesse sentido, Scaramucci (1993, p. 93) ressalta ser necessário "conceber a avaliação de forma diferente", para que a sua função educativa prevaleça. Para a autora, a avaliação é um instrumento "de que dispõe o professor e a escola para a consecução de seus objetivos e do contínuo aprimoramento do processo de ensino/aprendizagem".

A avaliação assume, dentro dessa proposta, um papel de redirecionar o processo, sendo o seu principal objetivo, segundo Scaramucci (1993), fornecer subsídios para, quando e se necessário, redimensionar a ação e a direção do processo de ensinar e aprender uma LE. Ecoando os princípios defendidos pela autora, Luckesi (2002), ao abordar a avaliação no contexto educacional, coloca que a avaliação ampara as tomadas de decisões frente à aprendizagem dos educandos, propiciando formas de se garantir a qualidade dos resultados esperados.

A importância da reflexão e do embasamento teórico consistente, no que se refere à avaliação, é retomada por Scaramucci (2004, p. 212), à medida que a autora reconhece que a ação de avaliar, "nas percepções 
e atitudes das pessoas, depende em grande escala de suas crenças". No que se refere ao processo de ensino/aprendizagem de LEC, Cameron (2001) salienta que a avaliação deve ter como foco o processo e não meramente o produto e aponta que professores devem ter uma clara concepção do processo de aprendizagem de línguas e do contexto sociocultural no qual este está inserido, devendo, portanto, buscar agir de forma crítica frente a esse processo, como também levar o aluno a compreender melhor a maneira como ocorre, entendendo seus resultados.

Caminhando na mesma direção, Scaramucci (2004, p. 213) acentua o caráter ameaçador da avaliação (1997), assim como a importância de os professores conduzirem o processo em sala de aula, envolvendo os alunos e também "coletando informações a respeito de avaliações e tarefas". Em nossa acepção, tal premissa alinha-se a princípios defendidos por vários teóricos na área de ensino/aprendizagem de línguas na infância, dentre eles Cameron (2001, 2003), Brewster, Ellis e Girard (2002), os quais acentuam a importância do envolvimento do aluno no processo avaliatório, visando a baixar o nível de tensão inerente ao processo e, portanto, obtendo melhores resultados.

Os princípios até então explicitados evidenciam-se claramente na metáfora utilizada por Cameron (2001) para definir o ensino/aprendizagem de LEC e a função da avaliação dentro desse processo. Sucintamente, o desenvolvimento do processo e, conseqüentemente, da aprendizagem, é comparado ao crescimento de uma planta, que ocorre em função dos nutrientes provenientes do meio, os quais são absorvidos por suas raízes, seguindo um ciclo de crescimento que ocorre de diferentes formas, em diferentes momentos.

A avaliação, segundo essa imagem, não está interessada unicamente na altura da planta, ou seja, no quanto ela cresceu. Em vez disso, o desenvolvimento está intimamente relacionado à qualidade de seu crescimento, sendo este o foco a ser avaliado. Dentro dessa concepção, em que possíveis problemas com o crescimento da planta servem para redirecionar a maneira como ela será tratada, retoma-se o conceito de avaliação com função educativa, defendida por Scaramucci (1997), em que esta é concebida como instrumento cuja função recai em redimensionar a ação dentro do processo de ensino/aprendizagem de línguas.

De acordo com Cameron (2001), o conceito de avaliação, conforme já explicitado, transcende a mera verificação, o que retoma os princípios defendidos por autores como Scaramucci (1993, 1997), Luckesi (2002), 
dentre outros. Dentro desse contexto, autores (CAMERON, 2001; BREWSTER; ELLIS; GIRARD, 2002; IOANNOU-GEORGIOU; PAVLOU, 2003; somente para citar alguns) que atuam dentro da área de ensino de LEC salientam a relevância de o processo avaliativo contar com instrumentos diversificados, ou seja, constituir-se, além das provas formais, de variadas outras formas que propiciem a avaliação da aprendizagem ao longo do processo, tais como observação, portfólios, auto-avaliação, dentre outros.

Convergindo com os princípios apresentados, Basso (2001, p. 116) sugere que incluamos o "aspecto qualitativo" dentro do processo de avaliação, atendo-nos a fatores como o porquê, o como, o o que e o para que nossos alunos aprenderam. A autora prossegue enfatizando que, além de portfólios, os jornais, os diários, as dramatizações, os jogos interativos, as entrevistas, as conferências e as amostras de textos orais e/ou escritos podem ser considerados "atividades avaliativas formativas". Corroboramos o pensamento da referida autora nesse sentido, como também quando argumenta que "testes e provas podem ser incluídos como formativos, desde que haja uma necessidade que não seja exclusivamente de classificar ou aprovar os alunos" (BASSO, 2001, p. 117).

Nesse sentido, Ioannou-Georgiou e Pavlou (2003) apontam que as principais razões para se avaliar a criança frente à sua aprendizagem de LE devem recair sobre a importância de se monitorar e auxiliar o seu progresso, estimular a motivação mediante os resultados positivos obtidos, planejar trabalhos futuros, bem como fornecer informações para as autoridades envolvidas e, principalmente, para a criança e seus pais. Cameron (2001) ressalta ser de grande importância a explicitação de objetivos e critérios da avaliação, a fim de que a criança e seus pais possam compreendê-los claramente.

Brewster, Ellis e Girard (2002, p. 245), por sua vez, entendem que a avaliação em LEC assume diferentes papéis, sendo estes estabelecidos conforme os objetivos a serem alcançados. Os referidos autores estabelecem cinco principais razões ${ }^{4}$ que sustentam a avaliação dentro

\footnotetext{
${ }^{4}$ Os termos originalmente usados pelos autores, ao abordarem as cinco razões principais da necessidade de avaliação dentro do processo de ensino/ aprendizagem de LE para crianças, são: formative, summative, informative, diagnostic e evaluative.
} 
do processo de ensino/aprendizagem de línguas na infância, asseverando, primeiramente, que a avaliação deve ser formativa, à medida que busca aumentar a motivação da criança. Além disso, esses teóricos asseveram que a avaliação deve ser, também, somativa, uma vez que visa a fornecer informações ao aluno sobre o seu progresso em momentos específicos. A avaliação deve ser, ainda, informativa, ao passo que objetiva conscientizar alunos, pais e autoridades sobre o desenvolvimento do aprendiz ao longo do processo; deve ser também diagnóstica, sendo que monitora as necessidades individuais do aluno. Finalmente, os autores salientam seu caráter avaliativo, por entenderem ser a avaliação um instrumento voltado a identificar as metas alcançadas.

Ainda no que se refere ao processo de avaliação em LEC, asseveramos que ele deve alinhar-se aos principais objetivos estabelecidos para esse ensino por autores como Cameron (2001), Moon (2000), Scott e Ytreberg (2004), Brester, Ellis e Girard (2002), dentre outros. Conforme já salientado, esses teóricos defendem que o processo de ensino/aprendizagem de LEC deve objetivar o desenvolvimento lingüístico, psicológico e sociocultural do aprendiz, fazendo da competência intercultural (BYRAM; DOYÉ, 1999) um de seus principais focos. Dessa forma, o processo avaliativo deve estar diretamente relacionado ao desenvolvimento das competências lingüísticocomunicativa e intercultural do aluno.

Nesse sentido, Ioannou-Gergiou e Pavlou (2003) pontuam que a avaliação deve contemplar o desenvolvimento das quatro habilidades de forma integrada, em situações reais e propositadas de interação na língua-alvo, do aprender a aprender, das atitudes e habilidades comportamentais e sociais, uma vez que esses pontos fazem parte dos objetivos lingüísticos, psicológicos e culturais defendidos para o ensino/ aprendizagem de LEC atualmente (ELLIS, 2004; ROCHA, 2006; entre outros).

Cameron (2001) ressalta a importância de abordarmos os conceitos de validade e confiabilidade dentro do processo de avaliação do ensino/ aprendizagem de línguas na infância, os quais são utilizados pela autora para descrever a qualidade técnica das práticas de avaliação. Segundo Cameron (2001), tais conceitos referem-se, na maioria das vezes, a avaliações de produto (as quais são abordadas pela autora como "testes"), podendo ser também aplicados a outras formas alternativas de avaliação. Uma avaliação é considerada válida quando mede com precisão e consistência 
aquilo que se propõe a medir (HUGHES, 1989). Ao elaborarmos uma avaliação, portanto, precisamos explicitar exatamente aquilo que queremos avaliar. Além disso, é importante que especifiquemos o que a avaliação proposta irá checar e que tipo de resultados poderemos obter através dela.

Para que uma avaliação seja considerada confiável, ela deve produzir os mesmos resultados, ou resultados muito próximos, caso essa avaliação seja aplicada aos mesmos alunos, em ocasiões diferentes, respeitando-se curtos espaços de tempo. A confiabilidade revela-se, também, se a avaliação mostrar resultados muito semelhantes se os mesmos alunos forem avaliados por pessoas diferentes (GIPPS; STOBART, 1993 apud CAMERON, 2001). Esse construto, contudo, pode ser afetado pelas condições sob as quais os alunos estejam sendo avaliados, pela forma como os professores transmitem as instruções ou, ainda, pela forma como os avaliadores corrigem um teste.

Hughes (1989) elenca algumas sugestões para tornar uma avaliação mais confiável. Dentre elas, podemos citar a inclusão de várias amostras de um mesmo item, a tentativa de não se deixar a avaliação muito aberta, a formulação de perguntas que não dêem margem a ambigüidades, a elaboração de questões claras e explícitas, a disponibilidade de gabaritos e/ou grade de respostas e, finalmente, a utilização de itens que permitam que a avaliação seja o mais objetiva possível.

O referido autor aponta, ainda, que existe uma tensão natural entre validade e confiabilidade, havendo sempre uma perda de um dos lados, ou seja, quando a validade é privilegiada, perde-se em confiabilidade e vice-versa. Nessa perspectiva, o avaliador deve procurar estabelecer um equilíbrio, tentando privilegiar o aspecto mais condizente com as necessidades de um determinado contexto. Segundo Cameron (2001), essa tensão acaba criando um dilema na educação. Uma forma de se obter um equilíbrio entre ambos os construtos, segundo a autora, está na identificação cuidadosa dos propósitos da avaliação.

\section{Metodologia de Pesquisa}

O presente estudo evidencia a pesquisa de natureza qualitativa e de cunho etnográfico, possuindo também caráter interpretativista, segundo Erikson (1986), André (2003) e Santos Filho e Gamboa, (2002). 
A triangulação dos dados, como possibilidade de aumentar a credibilidade dos resultados obtidos (DAWSON, 1982; REIS, 2005), foi garantida através da utilização de diferentes tipos de instrumentos. Foram primeiramente aplicados questionários abertos com o intuito de obtermos informações a respeito das concepções de avaliação dos participantes, bem como suas idéias a respeito da avaliação proposta pelo LD em uso. Entrevistas, também abertas e seguidas de suas respectivas transcrições (ERICKSON, 1986), foram utilizadas como meios de se propiciar o confronto de informações obtidas nos questionários.

O cenário da pesquisa consiste no processo de ensino/ aprendizagem de LE para crianças, concretizado através de um Projeto de Línguas implantado nas séries iniciais ( $1^{\underline{a}}$ a $4^{\underline{a}}$ ) do Ensino Fundamental das escolas públicas de uma cidade do interior paulista. O objeto de estudo, por sua vez, é a avaliação proposta pelo livro didático em uso no referido projeto. O mencionado livro didático, publicado no ano de 2003 por uma editora internacional atuante no Brasil, destina-se ao ensino de inglês para crianças brasileiras. Seus autores são duas profissionais, sendo uma delas estrangeira e a outra brasileira.

Foram quatro os participantes da pesquisa, sendo eles aqui chamados de P1, P2, P3 e P4. Todos eles são formados em Letras e atuantes dentro do contexto de ensino/aprendizagem focado neste estudo, por períodos de tempo que variam de seis meses a três anos.

\section{Análise dos Dados}

\section{Análise da visão explícita de avaliação proposta pelo MD}

Partindo-se do pressuposto que a avaliação deve servir aos objetivos propostos para o processo de ensino/aprendizagem (CAMERON, 2001), para que cumpramos o objetivo de investigar a avaliação proposta pelo LD em questão, faz-se necessário que consideremos as diretrizes estabelecidas para o ensino de LE para crianças, as quais são explicitadas no manual do professor.

O curso proposto segue princípios de uma abordagem comunicacional frente ao ensino de LE (ALMEIDA FILHO, 1993, 2005), corroborando concepções sociointeracionais de linguagem e de aprendizagem (VYGOSTSKY, 1978, 1998, 2001), as quais são, por sua vez, defendidas pelos PCN-LE. Ressalta-se que estão salientados no material em questão 
os princípios da educação como forma de construção da cidadania crítica, de valores e de atitudes positivas e cooperativas, também estabelecidos pelos PCN-LE, os quais já foram neste estudo relacionados a pressupostos comunicativos.

Segundo parâmetros descritos pelos autores, os princípios básicos que norteiam o trabalho proposto pelo LD consistem em garantir que a LE, através do trabalho envolvendo as quatro habilidades, seja ensinada de forma contextualizada e próxima da realidade do aluno, mantendo sempre em foco que a aprendizagem ocorra através da língua, não se restringindo unicamente ao saber sobre ela, conforme excertos abaixo:

[1] Garantir a prática da língua de forma contextualizada e próxima da realidade de crianças dessa faixa etária (Manual do Professor, p. 2).

[2] O foco está na utilização da língua, aprender através da língua e não apenas sobre ela (Manual do Professor, p. 2).

Objetivos discursivos, situacionais e atitudinais são propostos, a fim de que o ensino da LE não se limite a objetivos lingüísticos, visando a propiciar o desenvolvimento da consciência crítica do aluno, através do questionamento, da construção de valores e de uma postura de respeito às diferenças. Da mesma forma, as interações proporcionadas através do uso do LD visam a desenvolver uma atitude de cooperação entre alunos, ao mesmo tempo que é propósito do ensino de LE promovido pelo material propiciar a interdisciplinaridade, o que pode ser constatado através dos exemplos que seguem, retirados do manual do professor.

[3] Delimitar objetivos outros, alem do lingüístico (..), para que o professor possa discutir valores com seus alunos e, desta forma, torná-los cidadãos transformadores, solidários e cooperativos (Manual do Professor, p. 2).

[4] Utilização do inglês como instrumento para o aprendizado de conteúdos de outras áreas do conhecimento, e sobre costumes e tradições de outros povos, (...) (Manual do Professor, p. 2).

É interessante notar o incentivo explicitado no LD ao uso da LE em situações reais fora do ambiente escolar, bem como a ênfase dada ao envolvimento dos pais no processo. Em uma seção específica do 
material, no qual é proposta a elaboração de pequenos projetos, temse como objetivo central "criar oportunidade para que os alunos usem a língua fora da sala de aula, de forma real, e estabelecer uma ponte entre a casa e a escola, de modo a permitir que os pais tenham uma idéia mais clara do que se passa nas aulas de inglês" (Manual do Professor, p. 6). Tais propósitos ecoam princípios comunicacionais e sociointeracionais, já justificadamente considerados consonantes neste estudo, que defendem que a língua seja aprendida de forma natural e que a aprendizagem da LE faça sentido para o aluno.

No que se refere ao processo de avaliação proposto pelo LD, encontra-se explicitada no Manual do Professor (p. 16) a importância de se fazer uma "observação contínua e detalhada dos alunos". Para tal, propõe-se uma ficha de registro envolvendo itens relacionados às quatro habilidades, bem como à participação, organização e "outros".

A partir do exposto acima, podemos concluir que a visão explícita de avaliação é que ela tem como foco o processo de desenvolvimento do aluno, concepção essa que é coerente com a visão de avaliação de processo, defendida por autores como Scaramucci (1997), Cameron (2001), dentre outros. O trecho abaixo, extraído do Manual do Professor, reforça a análise apresentada.

[5] Entendendo avaliação como parte integrante do processo educacional e como fonte de informações sobre o processo de aprendizagem, sugerimos que o professor observe atentamente seus alunos durante as aulas e crie oportunidades para que eles se expressem livremente (p. 17).

Ao definir a avaliação como instrumento capaz de fornecer informações sobre o processo, a visão explícita que se tem é a da avaliação como instrumento capaz de fornecer um diagnóstico da evolução da aprendizagem do aluno e redirecionar o ensino, estando em consonância, portanto, com o referencial teórico adotado neste estudo, que defende a função educativa da avaliação (SCARAMUCCI, op. cit.).

É importante ressaltar que a ênfase dada à observação durante as aulas, sugerida pelo MD, é considerada um importante instrumento de avaliação dentro do processo de ensino/aprendizagem de LE para crianças, conforme apontam Cameron (op. cit.) e Ioannou-Georgiou e Pavlou (2003), entre outros. 
A concepção de que a avaliação deve ocorrer através de variados instrumentos, conforme defendem autores como Brewster, Ellis e Girard (2002), Cameron (op. cit.) e Scaramucci (1997), encontra-se explicitada no LD, à medida que são apresentadas, ainda que brevemente, outras possíveis formas de avaliar o aluno além dos testes, conforme mostra o excerto abaixo:

[6] (...) o professor poderá utilizar testes (sem confundi-los com o processo de avaliação), discutir os resultados com os alunos, promover apresentações de diálogos (...), músicas, (...) enfim, procurar ter e fornecer informações sobre e durante o processo de aprendizagem e não apenas sobre o produto da aprendizagem.

É interessante pontuarmos que, conforme também parece evidenciar o excerto acima, os testes não fazem parte do processo de avaliação. Nesse sentido, buscando apoio em Scaramucci (1997), Rolim (2004), entre outros, consideramos os testes ou provas formais como instrumentos integrantes do processo avaliatório, não podendo ser tomados, contudo, como únicos instrumentos passíveis de avaliar a aprendizagem e direcionar o processo educativo, ou tampouco como instrumentos de avaliação que se limitem a focar erros e acertos dos alunos, distanciando-se de sua função de nortear o ensino.

Sugestões mais específicas para outras formas de avaliação, principalmente no que diz respeito à oralidade, encontram-se expressas no LD, e constituem-se na utilização dos projetos e cartazes propostos por ele.

Ressalta-se que a auto-avaliação, instrumento apontado como outra possível e importante forma de avaliação, faz parte do LD e explicitamente tem como objetivo levar os alunos a "refletir sobre o que realmente aprenderam" (Manual do Professor, p. 5). Esse é um momento apontado pelo LD em que a avaliação assume seu caráter diagnóstico, uma vez que representa "uma ótima oportunidade para o professor tomar conhecimento do conteúdo que deve ser revisado" (Manual do Professor, p. 5).

Podemos concluir, portanto, que a visão de avaliação explícita no LD parece estar de acordo com as visões de linguagem e aprendizagem que ancoram o material, bem como com concepções não reducionistas de avaliação. 


\section{Análise da visão implícita de avaliação do LD a partir da avaliação formal por ele proposta}

Os testes apresentados pelo LD fazem parte da avaliação formal proposta pelo material, conforme ilustra trecho que segue: "apresentamos a seguir um conjunto de testes (...) que pode ser fotocopiado pelo professor e utilizado em suas avaliações formais" (Manual do Professor, p. 17).

A avaliação formal é também um instrumento importante dentro do processo de avaliar. Sendo considerada como um dos procedimentos relevantes, autores apontam que ela não deve ser descartada, porém não deve ser utilizada como o único instrumento de avaliação. Nesse sentido, Demo (1996, p. 54-62) ressalta que "a prova formal necessita de limites, sendo importante a tentativa de superá-la, usando-se outros instrumentos de avaliação, principalmente nas escolas". Iannou-Georgiou e Pavlou (2003), ao referirem-se à avaliação formal dentro do processo de ensino/ aprendizagem de LE para crianças, asseveram que esse instrumento é importante, à medida que nos possibilita avaliar se o aluno atingiu certos objetivos específicos dentro do processo em questão.

No que se refere à avaliação sugerida pelo LD, ao analisar sua proposta de testes, podemos concluir que apresenta alguns pontos que estão em conflito com as diretrizes estabelecidas pelo próprio material para o ensino de LE.

Primeiramente, podemos observar que as atividades propostas na avaliação formal não são contextualizadas, o que as distancia da realidade do aluno, não se apresentando, portanto, fortemente significativas para ele. Tal fator contrapõe-se a princípios sustentados por abordagens comunicacionais e sociointeracionais, as quais explicitamente ancoram o LD e defendem que a aprendizagem deva ocorrer através de interações que façam sentido para o aluno.

Outro ponto da avaliação formal que parece estar dissonante dos princípios explicitados no LD, o qual aponta para a necessidade desse ensino ter objetivos psicológicos e culturais, além de lingüísticos, conforme também advogam teóricos da área (CAMERON, 2001; BREWSTER et al., 2002; BRUMFIT et al., 1995, entre outros), consiste na ausência de atividades voltadas para o desenvolvimento de valores e atitudes, bem como exercícios que envolvam aspectos culturais. Da mesma forma, não constam na avaliação formal atividades que 
possibilitem o acompanhamento do progresso do aluno quanto aos objetivos voltados à metacognição, ou seja, ao aprender a aprender (BRUNER, 1986), igualmente defendidos pelo próprio material e por estudiosos envolvidos com o ensino de LE para crianças. Os objetivos interdisciplinares propostos pelo LD também não são abordados na avaliação formal.

Podemos concluir, dessa forma, que a avaliação formal apresentada pelo LD distancia-se dos princípios explicitados por ele, em alguns pontos, e conduzem à análise de que a visão implícita de avaliação consiste na verificação de objetivos lingüísticos, desprovidos de real sentido para o aluno e não relacionados a outras habilidades ou capacidades do aprendiz.

Faz-se necessário ressaltar aqui que a abordagem que norteia a avaliação formal sugerida pelo LD é consonante com a visão de avaliação como um ato de verificação. Nesse sentido, devemos apontar que é exatamente esse o objetivo proposto para o instrumento pelo LD, uma vez que é apresentado com um "conjunto de testes (grifo nosso)", conforme já ilustrado. Porém, a nosso ver, dentro do contexto em que está inserida, a avaliação distancia-se de objetivos instrumentais, uma vez que o objetivo central do ensino de LE para crianças recai sobre o seu papel formativo, ou seja, desenvolver as crianças "lingüisticamente, psicologicamente e culturalmente" (BREWSTER; ELLIS; GIRARD, 2002).

Portanto, a avaliação formal dentro do processo de ensino de LE para crianças deve ser também um instrumento que possibilite avaliar o processo frente aos objetivos propostos para esse ensino como um todo, não se restringindo a objetivos lingüísticos unicamente, como ocorre na avaliação proposta pelo LD em questão.

Dentro dessa perspectiva, no que se refere ao conceito de validade de construto da avaliação, podemos concluir que encontra-se comprometido, uma vez que não foram abordados todos os objetivos propostos pelo LD, os quais visam ao desenvolvimento integral da criança, e não somente ao seu desenvolvimento lingüístico.

No que se refere ao conceito de confiabilidade, em contrapartida, podemos concluir que a avaliação proposta pode ser considerada confiável, à medida que não parece oferecer dificuldades quanto à sua mensuração, se aplicada em diferentes momentos e contextos, devido à sua explícita objetividade. No entanto, não podemos validar tal conclusão sem que estudos futuros venham a confirmá-la. 
Evidencia-se, a partir do conflito explicitado entre validade e confiabilidade dentro da avaliação proposta, a tensão inerente entre tais conceitos, apontada por autores como Cameron (2001) e Hughes (1994), entre outros.

É importante ressaltar que, partindo-se dos objetivos propostos para o ensino de LE pelo material, a análise dos dados nos remete à dicotomia existente entre o que está explícito no LD, ou seja, diretrizes e princípios estabelecidos para nortear o ensino de LE adotados pelo material, e o que se encontra implícito no LD, inferido através da análise da avaliação por ele proposta.

\section{A análise das crenças dos professores sobre a avaliação proposta}

Através dos dados provenientes dos questionários e das entrevistas, podemos concluir que todos os professores, ao definirem o que é avaliar, utilizam-se de palavras que nos remetem a uma visão de linguagem e aprendizagem característica de abordagens tradicionais, em que o aluno era visto como uma tabula rasa e o professor como o detentor de um conhecimento que deveria ser transmitido ao aluno. Podemos perceber também que a palavra mais utilizada por eles ao apresentar uma definição de avaliação foi "verificar", o que, por sua vez, remete-nos a uma visão também tradicionalista e reducionista da avaliação.

Os trechos das entrevistas apresentados abaixo ilustram a referida análise.

[7] (...) Avaliar para mim é constatar (...) preciso saber se ele (o aluno) está realmente aprendendo o que eu estou passando (...) (P1 Entrevista).

[8] (...) Avaliar é importante porque é uma forma de ver se o aluno aprendeu o que a gente ensinou, se a gente passou certo a matéria (...) (P2 - Entrevista).

[9] (...) Ver se a gente tá conseguindo passar bem o que a gente quer passar (...) (P3, - Entrevista).

Os trechos a seguir, extraídos dos questionários, reforçam a análise apresentada.

[10] A avaliação é uma "ferramenta" que o professor lança mão para "medir" ou analisar o nível de absorção da aprendizagem do aluno (P1 - Questionário). 
[11] Verificar se o que ensinei foi assimilado... (P4 - Questionário).

Contudo, todos os participantes apontaram a avaliação como um indicador da necessidade (ou não) de retomar alguns conteúdos e/ou de promover algumas mudanças quanto aos procedimentos utilizados no processo de ensino/aprendizagem. Dessa forma, podemos concluir que a visão implícita através das colocações é consonante com a concepção de avaliação como um instrumento que pode diagnosticar a qualidade e eficácia do processo, conforme apontam Luckesi (1986/ 2003), Brewster, Ellis e Girard (2002), entre outros, ao defenderem a função diagnóstica da avaliação.

[12] (...) Com isso podemos voltar ou acelerar o ensino, ou mudar a estratégia (P3 - Questionário).

[13] A avaliação dever ser diária, e não marcado data (P4 - Questionário).

[14] (...) Assim saberemos se a metodologia precisa ser mudada (P1 - Questionário).

Reforçando as concepções apresentadas, três professores mencionaram em suas falas a importância de se conceber a avaliação como um processo (SCARAMUCCI, 1997; CAMERON, 2001), dentre outros), o que nos leva à conclusão de que a visão dos professores distancia-se daquela que determina o produto como foco central da ação de avaliar, conforme mostram os excertos abaixo.

[15] (...) de várias maneiras... tenho que estar atenta a todas as reações e ações dos meus alunos a cada pergunta (...) avaliando tudo, a participação dentro de cada exercício (P1 - Entrevista).

[16] Avaliar é uma ação constante (...) (P1 - Questionário).

[17] (...) (devemos avaliar) de todas as formas possíveis, pois cada um tem uma forma de assimilação (P2 - Questionário).

[18] (...) avaliar é ver o resultado meus e dos meus alunos em todo o processo (...) (P4 - Entrevista).

[19] (...) acho que (devemos avaliar) de todas as formas (P2 Entrevista).

[20] (...) eu acho que tem que avaliar constantemente (...) (P3 Entrevista). 
Todos os participantes, com exceção de P4, consideram que a avaliação formal, apesar de não ser o único, é um instrumento importante de avaliação, o que reflete as concepções defendidas por Ioannou-Georgiou e Pavlou (2003), Demo (1986), entre outros.

[21] (...) precisa, burocraticamente precisa (da avaliação formal), passar nota lá (...) (P4 - Entrevista).

É interessante notar que a maioria dos professores (03) relaciona a avaliação formal à avaliação escrita, somente. No que diz respeito a diferentes instrumentos de avaliação, apenas um participante mencionou a auto-avaliação como relevante dentro do processo.

Todos os participantes apontaram que fizeram modificações nos testes apresentados pelo livro didático, ressaltando que isso se fazia necessário, uma vez que a avaliação deve estar adequada aos objetivos propostos e às necessidades dos alunos, as quais variam de aluno para aluno, de sala para sala. É importante mencionar que os professores julgam a avaliação proposta muito fácil e sentem a necessidade de complementá-la de alguma forma. Textos, de um modo geral, foram algo que os professores julgam que deveria ser adicionado à avaliação apresentada pelo LD em questão.

[22] (...) um texto, talvez eu colocasse um texto. Não tiraria nada, mas aumentaria um texto (...) (P1 - Entrevista).

[23] Eu acho que ela é boa (...) mas é um pouco fácil para o nível das crianças (P2 - Entrevista).

[24] (...) Acho que poderia ir um pouco além (...) eu acredito que elas são fáceis (P4 - Entrevista).

[25] Eu procuro dificultar um pouco mais (P4 - Questionário).

[26] Eu acho que tem que ter leitura (...) eu acho que faltou bastante coisa (...) acho que ficou meio repetitiva (P3 - Entrevista).

[27] Eu não sei (...) eu acho que é tudo tão objetivamente lingüístico, tinha que ter alguma coisa mais interpretativa, não sei, ou atitude (...) é mais a gente que fala de atitude (P4 - Entrevista).

É pertinente apontarmos que os participantes não explicitaram quais textos deveriam ser colocados e qual a forma de abordá-los, a fim de que eles contribuam para um ensino/aprendizagem pautado por uma abordagem de língua como comunicação. Isso implica a possibilidade 
de os participantes estarem fazendo uso de textos embasando-se em uma visão estruturalista de linguagem e leitura, com foco na gramática somente, o que pouco acrescentaria no sentido de tornar a avaliação formal mais condizente com os construtos defendidos neste estudo.

Apenas um participante (P4) abordou o fato de a avaliação sugerida pelo LD não conter aspectos atitudinais e culturais, aparentando consciência sobre o conflito verificado entre os objetivos propostos para o curso e os objetivos abordados na avaliação sugerida.

\section{Considerações Finais}

Os resultados obtidos através deste estudo evidenciam que a avaliação proposta pelo LD apresenta dicotomia entre os objetivos e referenciais teóricos explicitados pelo material e as visões implícitas na avaliação. Conflitos dessa ordem parecem ser comuns dentro do processo de ensino/aprendizagem de LE, levando-nos a concluir que a questão central passa a ser como oferecer possíveis formas de se lidar com a situação de confronto entre o explícito e o implícito.

A avaliação formal sugerida pelo LD constitui-se principalmente de atividades descontextualizadas, com foco nas habilidades lingüísticas. Em contrapartida, os objetivos explicitados para o ensino/ aprendizagem de LE para crianças estão calcados principalmente em concepções sociointeracionistas de linguagem e de aprendizagem. Não constam na referida avaliação itens que abordem aspectos atitudinais, culturais e do aprender a aprender, defendidos nas diretrizes explicitamente estabelecidas para o curso. Concluímos, portanto, que a avaliação distancia-se do objetivo principal desse ensino, que é o de formar cidadãos críticos e participantes através do ensino de LE, comprometendo, dessa forma, sua validade.

No que se refere às crenças dos professores participantes desta pesquisa frente à avaliação proposta, podemos concluir que os mesmos não vêem a avaliação formal como o único instrumento a ser utilizado no processo de avaliar. Tal abordagem está condizente com as diretrizes estabelecidas no LD, as quais, por sua vez, são consonantes com os referenciais teóricos adotados neste estudo.

Os participantes partilham da concepção defendida pelo LD e corroborada nesta pesquisa de que a avaliação deve ter como foco 
primário o processo, sendo sua função primordial a de oferecer subsídios para o (re)direcionamento do ensino em questão. Ressaltase que os participantes mencionaram fazer alterações na avaliação proposta, com o intuito de promover adaptações ao contexto em que estão inseridos, o que está em consonância com os princípios que defendem que a avaliação deve estar condizente com os objetivos propostos e com as necessidades específicas do contexto.

Ao descreverem a avaliação sugerida pelo LD como "fácil", apontando a necessidade de ser complementada com elementos que levem o aluno a pensar e a refletir, bem como com aspectos de caráter atitudinal, cultural e interdisciplinar, os participantes, de certa forma, reforçam a análise apresentada, a qual mostra que a avaliação não aborda todos os objetivos propostos e estabelecidos para o ensino em foco.

As crenças explícitas dos participantes parecem refletir uma visão menos tradicional de avaliação, corroborando em muitos aspectos uma concepção mais abrangente e menos reducionista do conceito de avaliar, o que é explicitamente defendido pelo LD. Contudo, faz-se necessário apontar que ao definirem o conceito, as palavras utilizadas pelos participantes remetem-nos a uma visão tradicionalista de avaliação, à medida que se referem à avaliação como um ato de "verificar o que foi assimilado pelo aluno".

Portanto, podemos inferir através da análise dos dados que tanto o LD como os participantes, em algum momento, apresentam visões contraditórias frente à ação de avaliar. Retomando a questão de conflito entre o dizer e o fazer, entre o explícito e o implícito, tão presente dentro do processo de ensinar e aprender LE, corroboramos o pensamento de autores como Dutra e Mello (2004), Magalhães (2004), Silva (2005), Silva, Rocha e Sandei (2005), entre outros, que defendem a prática (crítico) reflexiva como o principal instrumento para suavizar a distância entre teoria, discurso e prática docente. Ressaltamos também que trabalhos futuros focando a prática dos participantes desse estudo contribuirão substancialmente para a melhor análise do processo em foco e, portanto, para encaminhamentos mais sólidos visando a um ensino mais efetivo e menos contraditório. 


\section{Referências Bibliográficas}

ALANEN, R. A Sociocultural approach to young language learners' beliefs about language learning. In: KALAYA, P.; BARCELOS, A. M. F. (Eds.). Beliefs about SLA: New Research Approaches, Kluwer Academic Publishers, p. 55-86, 2003.

ALMEIDA FILHO, J. C. P. Dimensões comunicativas no ensino de linguas. Campinas: Pontes. 1993.

Parâmetros atuais para o ensino de português lingua estrangeira. Campinas: Pontes, 1997.

Lingüistica aplicada, ensino de linguas e comunicação. Campinas, SP: Pontes, 2005.

ANDRÉ, M. E. D. A Etnografia da prática escolar. Campinas, SP: Papirus, 2003.

BAKHTIN, M. V. Marxismo e filosofia da linguagem. São Paulo: Hucitec, 2004. [1929].

BARCELOS, A. M. F. A cultura de aprender língua estrangeira (inglês) de alunos de Letras. 1995. Dissertação (Mestrado em Lingüística Aplicada) Instituto de Estudos da Linguagem, Unicamp, Campinas.

BARCELOS, A. M. F. Understanding teachers' and students' language learning beliefs in experience: A Deweyan Approach. 2000. Tese (Doutorado) - The University of Alabama, Tuscaloosa.

BARCELOS, A. M. F. Metodologia de pesquisa das crenças sobre aprendizagem de línguas: estado da arte. Revista Brasileira de Lingüistica Aplicada, v. 1, n. 1, p. 71-92, 2001.

BARCELOS, A. M. F. Researching Beliefs about SLA: A Critical Review. In: KALAJA, P.; BARCELOS, A. M. F. Beliefs about SLA: New research approaches. Netherlands: Kluwer Academic Publishers, 2003. p. 7-33.

BARCELOS, A. M. F. Crenças sobre aprendizagem de línguas, Lingüística Aplicada e ensino de línguas. Linguagem e Ensino, v. 7, n. 1, p. 123-156, $2004 a$.

BARCELOS, A. M. F. Crenças sobre aprendizagem e ensino de línguas: o que todo professor de línguas deveria saber. In: CAMPOS, M. C. P; GOMES, M. C. A. (Org.). Interações dialógicas: linguagem e literatura na sociedade contemporânea. Viçosa: Editora UFV, 2004b. p. 15-40.

BASSO, E. A. A construção social das competências necessárias ao professor de lingua estrangeira: entre o real e o ideal. Um curso de Letras em estudo. 2001. Tese (Doutorado em Lingüística Aplicada) - Unicamp/IEL. Campinas. 
BASSO, E. A. A Avaliação no contexto de ensino-aprendizagem de linguas. UNESPAR, Campo Mourão, 2003. Mimeografado.

BRASIL. Secretaria de Educação Fundamental. Parâmetros Curriculares Nacionais: terceiro e quarto ciclos do Ensino Fundamental: Língua estrangeira: Brasília: MEC/SEF, 1998.

BREWSTER, J.; ELLIS, G.; GIRARD, D. The Primary English Teacher's Guide New Edition. London: Penguin, 2002.

BRUMFIT, C.; MOON, J.; TONGUE, R. Teaching English to Children: From Practice to Principle. Essex: Longman, 1995.

BRUNER, J. S. The Culture of Education. Cambridge: Harvard University Press, 1986.

BYRAM, M.; DOYÉ, P. Intercultural Competence and Foreign Language Learning in the Primary School. In: DRISCOLL, P.; FROST, D. (Eds.). The Teaching of Modern Foreign Languages in the Primary School. Routledge, 1999.

CAMERON, L. Teaching English to Young Learners. Cambridge: Cambridge University Press, 2001.

CAMERON, L. Challenges for ELT from the expansion in teaching children. ELTJournal, v. 57/2, p. 105-112, April 2003.

COOK, G. Applied Linguistics. Oxford: Oxford University Press, 2003.

COX, M. I. P; ASSIS-PETERSON, A. A. O professor de inglês: entre a alienação e a emancipação. Linguagem E Ensino, v. 4, n. 1, p. 11-36, 2001.

DAWSON, J. A. Qualitative Research Findings: What do we d/o to improve and estimate their validity? Trabalho apresentado no Encontro Annual da Aera, Nova York, 1982.

DEMO, P. Avaliação sob o olharpropedêutico. Campinas: Papirus, 1996.

DUTRA, D. P.; MELLO, H. (Org.). A gramática e o vocabulário no ensino de inglês: novas perspectivas. Belo Horizonte: Faculdade de Letras da UFMG, POSLIN, 2004.

ELLIS, G. Developing intercultural competence with children in the English language class. Thresholds, 2004. Disponível em: <w.w.w.counterpointonline.org/doclibrary/british_council/download/179/Thresholds-1-GailEllis.pdf >. Acesso em: 18/12/2004.

ERICKSON, F. Qualitative Methods in Research on Teaching. In: WITTROCK, M. (Org.). Handbook of Research on Teaching. Nova York: MacMillan, 1986. 
FREIRE, P. Pedagogia do oprimido. Rio de Janeiro: Paz e Terra, 1988.

FREIRE, P. (Org.). Educação como prática da liberdade. Rio de Janeiro: Paz e Terra, 1982.

FREIRE, P. Educação como prática da liberdade. São Paulo: Paz e Terra, 1996.

FREIRE, P. Pedagogia da autonomia: saberes necessários à prática educativa. São Paulo: Paz e Terra, 2004.

HOUSE, S. An introduction to teaching English to children. London: Richmond Publishing, 1997.

HUGHES, A. Testing forlanguagesteachers. Cambridge: Cambridge University Press, 1989.

IOANNOU-GEORGIOU, S.; PAVLOU, P. Assessing young learners. Oxford: Oxford University Press, 2003.

KALAJA, P. Students beliefs (or metacognitive knowledge) about language SLA reconsidered. International Journal of Applied Linguistics, v. 5, n. 2, p. 191-204, 1995.

KALAJA, P. Research on students' beliefs about SLA within discoursive approach. In: KALAJA, P; BARCELOS, A. M. F. (Eds.). Beliefs about SLA: New Research Approaches, p. 87-198. Klueger Academic Publishers, 2003.

LUCKESI, C. C. Avaliação da aprendizagem escolar. São Paulo: Cortez, 2002.

LUZ, G. A. O ensino de inglês para crianças: uma análise das atividades em sala de aula. 2003. Dissertação (Mestrado em Estudos Lingüísticos) Faculdade de Letras, Universidade Federal de Goiás.

MAGALHÃES, M. C. C. A linguagem na formação de professores reflexivos e críticos. In: MAGALHÃES, M. C. C. (Org.). A formação do professor como um profissionalcrítico: linguagem e reflexão, Campinas, SP: Mercado de Letras, 2004. p. 59-86.

MENEGHINI, C. M. A abordagem de Paulo Freire no ensino de espanhol como língua estrangeira. In: CONSOLO, D. A.; VIEIRA-ABRAHÃO, M. H. (Org.). Pesquisas em Lingüistica Aplicada: ensino e aprendizagem de língua estrangeira. São Paulo: Editora Unesp, 2004. p.155-180.

MOITA LOPES, L. P. Oficina de Lingüística Aplicada: a natureza social e educacional dos processos de ensino/aprendizagem de língua. Campinas: Mercado de Letras, 1996. 
MOON, J. Children Learning English. Oxford: Macmillan Heinemann, 2000.

NESPOR, J. The role of beliefs in the practice of teaching. Journal of Curriculum Studies, v. 19, p. 317-328, 1987.

PAJARES, F. M. Teachers' beliefs and educational research: cleaning up a messy construct. Review of Educational Research, v. 62, n. 3, p. 307-332, 1992.

OLIVEIRA SANTOS, E. M. Abordagem comunicativa intercultural (ACIN): Uma proposta para ensinar e aprender língua no diálogo de culturas. 2004. Tese (Doutorado em Lingüística Aplicada) - Instituto de Estudos da Linguagem, UNICAMP, Campinas.

PENNYCOOK, A. Critical pedagogy and Second Language Education. System, v. 18, n. 3, p. 303-314, 1990.

PRABHU, N. S. The Dynamics of the Language Lesson. Tesol Quartely, 26 (2), 1992.

PRABHU, N. S. A dinâmica da aula de língua. Contexturas - Ensino Crítico de Lingua Inglesa, n. 5, p. 79-96, 2000/2001.

PRABHU, N. S. Communication: Help or Hindrance to Language Learning?. English Teaching Profesional, n. 4, p. 21-23, 2003

REGO, T. C. Vygotsky: uma perspectiva histórico-cultural da educação. Petrópolis: Vozes, 2004.

REIS, S. Reflexões sobre uma jornada com destino à pesquisa. In: GIMENEZ, K. M. P. (Org.). Contribuições na área de linguas estrangeiras. Londrina: Moriá, 2005. p. 75-90.

ROCHA, C. H. Provisões para ensinar LE no Ensino Fundamental de $1^{\underline{a}} a 4^{\underline{a}}$ Séries: dos parâmetros oficiais e objetivos dos agentes. 2006. Dissertação (Mestrado em Lingüística Aplicada) - Instituto de Estudos da Linguagem, UNICAMP, Campinas.

ROLIM, A. C. de O. A cultura de avaliar de professores de línguas estrangeira (inglês) no contexto da escola pública. In: ROTAVA, L.; LIMA, M. S. (Org.). Lingüística Aplicada: relacionado teoria e prática no ensino de línguas. Ijuí: Ed. Unijuí, 2004. p. 139-164.

SANTOS FILHO, J. C.; GAMBOA, S. S. (Org.). Pesquisa educacional: quantidade-qualidade. São Paulo: Cortez, 2002.

SCARAMUCCI, M. V. R. Dúvidas e questionamentos sobre a avaliação em um contexto de línguas. Outras Palavras. Semana de Letras, 5, Maringá. Anais. Universidade Estadual de Maringá, 1993. 
SCARAMUCCI, M. V. R. Avaliação de rendimento e ensino-aprendizagem de português como língua estrangeira. In: ALMEIDA FILHO, J. C. P. (Org.). Parâmetros atuais para o ensino de português lingua estrangeira. Campinas: Pontes, 1997. p. 75-88.

SCARAMUCCI, M.V.R. O efeito retroativo da avaliação no ensino/aprendizagem de línguas: o estado da arte. Trabalhos em Lingüística Aplicada. Universidade Estadual de Campinas. IEL Campinas, 43 (2), p. 201-360, jan.-jun. 2004.

SCOTT, W. A; YTREBERG, L. Teaching English to Children. London: Longman, 1990.

SILVA, K. A. Crenças e aglomerados de crenças de alunos ingressantes em Letras (Inglês). 2005. Dissertação (Mestrado em Lingüística Aplicada) Instituto de Estudos da Linguagem, UNICAMP, Campinas.

SILVA, K. A. Crenças sobre o ensino e aprendizagem de linguas na Lingüistica Aplicada: Um panorama histórico dos estudos realizados no contexto brasileiro, 2005. No prelo.

SILVA, K. A.; ROCHA, C. H.; SANDEI, M. L. R. A importância do estudo das crenças na formação de professores de línguas. Contexturas: Ensino Crítico de Inglês, APLIESP, v. 8, p. 19-40, 2005.

SCHÖN, D. A. The Reflective Practitioner. Nova York: Basic Books, 1983.

SMITH, J. Teacher's work and the politics of reflection. American Educational Research Journal, v. 29 n. 2, p. 267-300, 1992.

SWAN, M. A Critical Look at the Communicative Approach (1). ELTJournal, v. 39/2, p. 2-12, 1985.

THOMPSON, G. Some misconceptions about Communicative Language Teaching. ELTJournal, v. 50, n. 1, p. 9-15.

UR, P. The Communicative Approach Revisited. LAURELS News, nov. 1995.

VIEIRA-ABRAHÃO, M. H. (Org.). Prática de ensino de língua estrangeira: experiências e reflexões. Campinas: Pontes Editores, Arte Língua, 2004.

VYGOTSKY, L. S. Mind in Society. Cambridge, MA: Harvard University Press, 1978.

VYGOTSKY, L. S. A formação social da mente. São Paulo: Martins Fontes, 1984/1998.

VYGOTSKY, L. S. A construção do pensamento e da linguagem. São Paulo: Martins Fontes, 2001. 
WIDDOWSON, H. G. Teaching Language as Communication. Oxford: Oxford University Press, 1978.

WILLIAMS, M.; BURDEN, R. L. Psychology for Language Teachers. Cambridge: Cambridge University Press, 1997.

ZEICHNER, K. M. A formação reflexiva de professores: idéias e práticas. Lisboa-Portugal: Educa, 1993. 


\section{ANEXO 1 - QUESTIONÁRIO}

1- O que é avaliar para você?

2- Por que devemos (ou não) avaliar nossos alunos? Explique.

3- Como devemos avaliar nossos alunos?

4- O que você acha do material didático em uso? Analise-o brevemente.

5- Você utiliza a avaliação proposta pelo material didático? Por que sim (não)? Analise-a

6- Quais as diferenças e semelhanças entre a sua avaliação e a do material didático?

\section{ANEXO 2 - ROTEIRO PARA A ENTREVISTA}

1- Você poderia, brevemente, falar para mim o que é avaliar para você?

2- Você acha importante avaliar seu aluno?

3- Como deveríamos avaliar o aluno?

4- Você usa a avaliação proposta pelo material didático?

5- O que você acha dessa avaliação? Ela reflete as atividades propostas pelo livro didático?

6- A avaliação proposta reflete as atividades que você propõe em sala?

7- Você acha que falta algo na avaliação proposta?

8- Você gostaria de acrescentar algo? Gostaria de abordar algo que não tenha sido perguntado? 